\title{
Risk Management Techniques and Performance of Construction: A Case of Project of GT Bank in Rwanda
}

\author{
Salafina Flavia $^{1}$, Dr. Claude Rusibana ${ }^{2}$ and Kirabo Joyce ${ }^{3}$ \\ 1 Research scholar MBA (Project Management), Mount Kenya University Rwanda \\ 2 Senior lecturer Mount Kenya University Rwanda \\ 3Lecturer Mount Kenya University Rwanda
}

\begin{abstract}
Risk management recognized as a vital physical exercise in order to reach well performance of building organization. Project constructions success is showed as performance with in goals of organization like time, price, quality, securities and surrounding sustainability purpose. Project construction within Rwanda and mainly region and the universal running a more effects of being good over budgeting and appreciably late. While some certificate price and time scheduled effects is inevitable with building organizations and it is capable to increase the effect management method to reduce their negative effects. The research guided by three specific objectives namely; to determine the extent which risk identification process influence performance of the construction project, study also was to site selection process effect performance of construction project and budgeting affect the performance of the construction project of GT bank. Descriptive design applied as key participants within construction industry were targeted population with 73 members who were the engineers, consultants, constructors and other staff of GTbank, sample size calculated is 42 by using Slovenes Formula. A research used all qualitative and quantitative technique of collecting information. Review of literature, corporal and message sent surveys and discussions were held to accumulate information by using SPSS Correlation analysis were pragmatic among risk management and financial performance. Notwithstanding of risk management was broadly experienced at $92 \%$, the process was informal, inadequate and no longer measured were established in break to remove the risk. Institution team members had unlike chances unto management the various impacts towards clients have good opportunities of managing high effects under planning stage by including awareness
\end{abstract}

professionals among making decision. The organization choice and wants to identify that happen through planning steps with in major organizations research and a lot without the participation of construction professional. The beginning plan growth was done without the participation of professional. This study plan recommended an official and managing effect of controlling to settle with in performance throughout in the preparation and with the participation of building specialized and surface operators. The study suggested that hazard controlling was combined among database as an inspection query for both leaners responsibility building connected studies. There is require for nonstop to growth seminar with within effects of institutions risk organization to all building qualified in Rwanda and precise those in build planning training and gaining department with all remote and running inventors. The ends of allocator and recipient must be partaking within needs to recognize at the early stepladders of project.

\subsection{Background of the study}

Globally, monetary services are absolute crucial to accomplish the project, it is immediately impacts on their daily -daily process, and in turn their presentation in terms of funding firms should be tracing monetary to ambiguous experiment with in Bangladesh 30 years (Abor and Quartey,2010). It has since become globally profits member as increasing activities of assisting small income populace out of death. All worldwide among the construction firms, the purpose of managing is to ensure the plans ended on the event, through planning and achieve project purpose (Kerzner $\mathrm{H}, 2000)$. Price and frame performance are the first procedures of planning succeed. Meanwhile project explain that success comes through whether covered within the planning profits and timely. 
Sub-Saharan Countries are facing through the challenges of insufficient project monetary resources. Building has a vital role due to development of various nations particularly processing nations improvement. Therefore, building firms finalize to the gross domestic products and employment rate among various countries, for this facts preferred function for developing economies development has vital multiplier effects (Morris, et al,.1988). it is provided the communications by building the physical facilitate requisite for the manufacture share of goods and armed forces. Obtaining monetary services is a key important with in monetary special nations development plan. achievement of building project great based on the effective utilization money flow Kerzner H (2003).

Many bank-sponsored edifice projects with in Rwanda familiarity cost variations and achievement impediment challenge and now and again total malfunction hence planning failure therefore, World Bank was more $50 \%$ within Africa till 2012. The World Bank's private arm, the IFC has explored that only half of its African project achievement (Lavagnon,et al.,(2012). The project running success items are timely, cost and quality are subsidiary to more goods achievement purpose (Collins, 2009). consequently, as the similar are construction plan with in Rwanda substandard while other achievement, whereby they are funding the identical companies.

In Rwanda, Kigali Convention Center built within 6 years while the contract period was less than three years. The general Auditors annual highlighted report delayed and costly over running within Bushenge hospital and inadequate cost among the project implementation of King Faisal growth planning staffs of general Auditor of position amount (OAG,et al.,2013). In Karongi District, construction works sponsored by the Development Bank of Rwanda (BRD) worth two billion Rwanda Francs for Kibuye Hospital had been significantly delayed.

Accomplishment within construction project is showed by its presentation in the achievement of the plan period, amount, excellence, safety and ecological sustainability purpose (Zhou, et al.,2007). Though hard performance due to both play-actors within construction industry, various banks- donate about construction planning within nation and normal region, where there is more effect poor improvement by bodily being good concluded disposition and significant late. World Bank plan both too often nosedive to spread their purpose due to by quantity of issues that could be managed awareness and damaged plan design, poor family management, delay amid the plan cataloguing and establish, interruptions throughout planning victory, cost over scores and association failure. Consequently, some degree of unfortunate cost and program presentation is predictable in building plan, it is prospective to improvement effects of organization approaches by minimizing bad risk and improving scheme performance. This facts is to dominant the effect organization performance under planning phase and building performance (Clough, et al., 2005). The effect of building planning stage including underprivileged capability explanation and improving planning depend on good information. The effect of management performance obligatory at this phases including effect sketch and empathy, the fashionable and engineer choice process, building site assessment and authentication, needed to respect and collaboration of the starting planning and schedule improvement (Wallace \& Blumkin, et al,2007). Danger profile consist of resulting positive investment by considering the risk required, risk capability and risk tolerance clients.

\subsection{Objectives of this Study}

\subsubsection{General Objective}

The general objective of this study was to determine the relationship between risk management techniques and performance of construction project of GTbank in Rwanda.

\subsubsection{Specific Objective}

1. To determine the extent to which risk identification process influence performance of the construction project of GTbank

2. To determine the extent to which site selection process affect performance of the construction project of GTbank

3. To determine the extent to which budget affect the performance of the construction project of GTbank

\subsection{Significance of the Study}

This study will have the important of where the result would inform construction industries knowledge and clients in Rwanda on the profit risk management at the planning phase on the planning performance. Preliminary cost and time suggested highlighting powered bottlenecks and costlier items due to suggested planning also the study will have vital role of forecasting findings which will indicates process performed and siting choice confirmed progress associated with planning phases.

\subsection{LITERATURE REVIEW}




\subsection{Introduction}

This chapter introduces the literature review of the study. It elaborates on the three types of literature, which include theoretical, empirical and critical literature. The chapter also discusses the theories relevant to the study and the conceptual framework which highlights the ways through which, the research variables influence each other

\subsection{Theoretical Review}

\subsubsection{The concept of Risk Management}

Start global the worldwide perception, the conception of Risk management is recognized in to day business global as a vital part of moral plan organization practices. It involves the systematic request of management strategies, measures and performs to the responsibilities of identification, examining, evaluating, giving and checking plan risk (Haneef, 2012). A risk management outline includes the possibility of the risk to be able accomplished, the procedure/systems and measures of managing risk and the characters and tasks of persons complicated in the risk management, (Hansel,.et al 2009). The outline must be complete sufficient to the capture all risks of plan is showing and to have flexibility to accommodation any revolution in the business actions.

\subsubsection{The Concept of Performance}

Take the country of plan performance (Ceric,.et al 2003), advised that the plan performance must be studied start the perception of merchandise performance as well as procedures performance. It is generally believed that every plan is of single nature, in fact they want a changed and depending way to deal with the plan leaders with in positive leadership styles can only accomplish effectively in positive plans. In the present study, the idea of agency theory has been used to increase plan performance through plan governance and other substitute variables like planning quality, planning period, and price and business risk. The superiority of the plan design and merchandise does not only quantity the plan performance then viewed as important determination of planning performance as meeting superiority values seems that contributing towards growth plan performance. Therefore, in the similar way, plan performance can be growth through increasing various quality connected factors such as incidence of evaluating client satisfaction, reflective influence, team contribution in reflective and the team influence to reflective (Ceric,.et al2003).

\subsubsection{The Concept of Project Risk}

Risk is introduction of the chance of economic or monetary loss, physical loss or injury or delay for insecurity connected with in the following a certain reason of action (Chapman C.B, et al 1983). Most researchers have explained risk and many definitions contain the influences of chances and the negative effects unto goals of planning. In this regardless impact management of the schedule risk does having roles probable to improve project presentation done speaking various blockades that could suspension the confident assumption of the project. When doesn't figure appearance which may include and data of making decision is noteworthy in assessing the option of contrasting instance.

Risk impacts building plan by unfavorably moving the planned costs, plan calendar and excellence of everything. With increased plan period and poor value can be communicated in the improved costs. Risk effect is frequently designed all qualitative and quantitative approach. Menace skill is the products of danger option and risk effect. Risk society is the technique that putative out, settles that both could be done to obtain the detached of the project within building of the schedule (Clark, et al., 1990).

\subsubsection{Project Cost performance}

Planning organization form of awareness monitor definition of price estimations as a development estimate of the financial incomes want to comprehensive planning action. So The truthfulness of the price evaluations preliminary from the planning stage of a scheme through to the caring estimation can affected the achievement or failure of a building plan. Most disappointments of building plan for the price growths (Gkritza \& Labi,et al 2008). The procedure of determining the plan economical includes gathering of the projected price of single action or effort packages to start approved price zero (PMI,. et al 2008). The planning economical that consequences from the preparation cycle must be sensible, achievable, and built contractually exchanged price and the declaration of effort. Therefore, basis for the economical is the past price, best estimations, or firms manufacturing values. The training obligated to be classified into deliberate manpower supplies, agreement of using money and treatment standby Enactment for findings principles are quantitative ability and comprise for example stuffs as fineness of exertion, amount of exertion, cost of exertion, and time-to-complete (Kerzner,.et al 2009).

\subsubsection{Project Time performance}

The planning timetable contain the strategic opening date and the strategic ending date for every activity. Therefore, planning schedule will be available the immediate for arrangement the stated about the principal of schedule in detail. 
Commonly, the arrangement chart is presented graphically through innovative drawings, tablet drawings, and strategy schedule for connection drawings. In fact, on the beginning of rising schedule arrangement the study and documented accepted by the planning organization group as the opening idea within the starting point dates and baseline finished dates. The starting point is the main element in the schedule controlled and period controlling. While Planning period performance is to establish procedures, relating and investigative schedule presentation for instance by actual opening and finishing dates, measurement completed, and long-term dated for working in the growth. Then performance degree for the use methods for instance established cost organization, calendar adjustment, schedule presentation guide. This system helped to ration the balance of schedule adjustment. Therefore, serious cable performance equals the quantity of block stable and the capacity of barrier required to support the spreading time and hence can helped to controller the schedule of position (PMI., et al.,2008).

\subsection{Empirical Literature}

Risk management is only of the nine awareness areas spread by the Plan Management Institute. Therefore, attendant knows as none information zones demonstrative of the practically both arrangements. For instance, the strategy organization institute of information space includes several of the planning organization methods. Effect controlling of challenge feature of the planning controlling. Often strategy management requires to know and to classify the beginning foundation of the consequence while to associated their possessions for the planning development. Effect managing the construction of the planning development for the location comprehensive and well-organized way to classifying, inspecting and replying the effect of completed the planning purposes (PMI., et al 2008; ICE, et al 2005). Major choices and influence on the excellent of arrangement and choice of building techniques are made at the first steps of a plan, making effect management at this steps very vital (Eskesen, Tengborg, Kampmann, \& Veicherts,. et al 2004) responding to the effect risks to accomplish the plan objectives (PMI, et al 2008; ICE,.et al 2005). Main decisions making and influence on the selection of arrangement and choice of building techniques are made at the early steps of a plan, making risk management at this steps is very important (Eskesen, Tengborg, Kampmann, \& Veicherts,. et al 2004). The building firms includes a lot players and is essentially compound. The major organizations building works are: housing, non- housing construction, weighty, road, utility, and manufacturing (Clough,. et al 2005).
Construction of plan can be the construction and renovation of present association services. Extreme construction working in Rwanda contains innovative community and secluded institute policies. Large construction plan shows their effect growth by the preparation, project and construction effort, several performers, use of more profits and their accessibility, chance ecological influences, always instable financial and radical location, and legal instructions.

Dangerous conclusions whole of the opening all currency progress strategy has main consequences for the common accomplishment of the strategy. Often The place affected by the community, form; efficient; sustainable; accomplishment and monetary efficiency; security; and lastly the creative requirements of the building (GSA., et al 2001). Therefore, policymaking near the position of construction place is vital effect organization exercise of the preparation step. Building Constructions intimate the location. So place take the heavy impact of construction strategy and also automatic features, therefore operation of the planning Take policymaking nearby place of venture is composite, slight planned and principles tasks (Adjuk., et al 2013). The residence select is a lifecycle choice and knows the balance between the original price of the actual land, the common charge for causing the organization, and the cost of employed capacity. Both factors must be carefully, in accumulation to the feature of the cost, and making decision. Building the correct choice in the location choice it confirms that the selection residence is applicable for the future clients; reductions the effect of unpredicted difficulties and their consequence on the calendar and economical; succeed projections of the stockholders and encourage modernization and imagination in the best process while grouping and prevailing the best performs.

Schemes are approved because of a marketplace demand, a commercial requirement, a customer demand, authorized requirement or a social essential. One of the methods in developing the plan idea is the top-down when decision making, representatives or senior of public servants find the conditions that need in development and try to find chances. The bottom-up method start by the community coming up with needs to take decision making, representatives or public servants to act to resolve a problem through a plan. Occupied and accurate examination of the current challenges, needs and chances is key to the accomplishment of the right planned project addressing the actual needs of exact target groups.

The challenge analysis the wrong phase of existing same situations regarding to settle the causes and 
impact associating between the identification issue. The difficulties caused included the explanation of timeframe and topic elicited also the majority issues were challenged by embattled individuals and receivers, the beginning task in terms of character term of the experiment three (3) to care examine and illustrative consequence connecting. Therefore, investigation persistence and acknowledged exact that are stockholders assign added importance and agreeable to overwhelmed. The problems examination complete foundation are progress set of applicable and also fixated plan purposes. Including stakeholder's agents with in right awareness and talents serious of the Good output. (Al-Hejji.,et al2006).The transformation requirement in the building steps that are often by stakeholders opposing and view of the plan. The aim such as revolution order can be unfortunate planning clarification and how the activities must be affected. Often, shareholder refer to transformed actions who can motivation the planning will be affected the strategy. Building steps are frequently as a shareholder's opposing thankfulness and interpretation of the plan. The object for instance, transformation instructions may be unfortunate planning explanation and how the effort can to be controlled. So their shareholders for occurs to the unlike gatherings who can inspiration the plan and persons who will be posh by the planning. Therefore, strategic has further participants far the planning assembly among the unlike boundaries and their consideration linked (Wang \&Huang., et al 2010). The desires of documentation process at the primary stages through input from both investor's is vital planning accomplishment.

The establishing of suitable plan and timetable is dangerous to achievement of building plan. The customer and plan mentor must be agreeing to the expectation price early period in the planning steps. This is serious steps in the price management procedures as wrong due to lowly plan performance. Imprecise preparation it leads good cooperation and variation with the neither customer, end-user, nor project group for being totally enough at the finished. It is common error at the steps of planning to use of calendar of space with in areas and related some past price without creation changes for more factors which affected building the price such as mass of the plan ,place, value improve as the date used, obtaining techniques, common excellence of the residence project, admission and place influences for instance condensed city, highway movement and pushover security, river dwelling, proposition efficiency in the local market, etc.(WBDG., et al2011).

First Assessments are advanced through the planning steps of the future plan with in the line of clients desires to spoken in the decided latitudinal requirement fleeting and within inexpensive boundaries to establish general possibility and price forecasts. So often based volume estimation is the highest general and belief by basic amount arrangement since again presented strategy with connected extent and environment. Therefore, first building calendar the suggestion construction of date, serious pathway objects and bargains foremost symbols. The initial building calendar recognizes the time ranging dates; total, or qualified to opening date; that a planning charge will be opening and proficient. The schedule permits suitable profits to be predictable and forecast period background to be documented. This assessed period provides the base for planning separate the responsibilities and the planning completed. Set Assessment and Examination Technique for linkage planning techniques supports to control wherever the highest effort must be made to keep a plan on calendar. Project estimation and review techniques is used to control the possibility of assembly limits by development of other strategies. Project estimation and review techniques have the capacity to assess the outcome of changes in the platform. Accepting Project estimation and review techniques measures can lead to decrease of the plan charge and calendar for well organize and advance preparation (Kerzner,.et al 2009). Project estimation and review techniques measures support the historical essential for the predictable conclusions, then permits to complementary period for conclusions.

Building Plans and Performance Achievement depends on achievement of performance. Several previous researches have been considered performance of building plans. (Kumar, R.,.et al 2005), this said that among of the principle reasons for the building manufacturing's poor presentation have been qualified to the unsuitability of the selected obtaining system. (Kumar, R,.et al 2005), this commented for three vital structures fundamental the dynamic of a plan performance, which are the work achievement structure, response things on efficiency and work excellence and effects from upstream stages to downstream stages. (Cheung,. et al 2004) recognized plan performance groups such as people, price, period, quality, security and fitness, environment, customer satisfaction, and communication. It is connected by (Navon,.et al 2005) that a controlled system is essential to classify factors affecting building plan energy. For each of the plan goals, any or more Plan Performance Signs is needed. (Kumar, R,.et al S2005), to gained that human features played vital role in influential the performance of plan. (Walliman, N,.et al 2011), said that both initial contractor participation and initial seller participation would reduce constructability related 
performance difficulties containing price related with postponements, rights, expenditures and revise, etc.

\subsection{Critical Review and research Gap Identification}

Refers to seeming the critical review there is no common assessment consequence among the transformed actors in the construction planning. Therefore importance of organization for the effect management of planning action is not only enough to recognized by the building firms (Walewski, Gibson, \& Vine,.et al 2002). Meanwhile not only that common view of the risk occurs, owner, stockholders, inventors, and construction have different objects and adverse relationship among the party of common.

The works assessment appearances that most researcher have absorbed on the change of methods for effect management and the character of safety management in the building plans. Whereas most literature review. recognize the effect management is a process, the difficult of how the process must be increase to construction of technique not every durable. Therefore, most literature reviews used techniques to construction actions as strategic and uniform production process like firms. However, the construction techniques so often have a superior construction for every planning that has load process and categories variations essential to the measures that are growth effort. Manufacturing measures for the period in the construction plans extended, which are development within the potentials of the effect and questionability happenings on the both value and chart. While the technique extensive period for several years, risk management it develops hypothetical and only other method is to added chance option of the amount. However, the literature reviews is available on how to examine the effect, so often very little recognition of the function that prolonged techniques period bring about the effect that can be precisely evaluate and quantity. Therefore, construction of businesses for occur the industrialize, the condition that are more effort still about the physical brands revolution and technique growth measures to harmonized other businesses. Occurs, most literature review construction wellbeing management does not speak the requirement for other operative presentation ideas for instance motivation ideas of the part effect management.

Common production procedures expect common or often unidentified Customer. Goods are communally developed then promoted. Though, the building procedures is single in that the Customer is recognized and plays an essential role in plan achievement is often in experienced. The stockholder or customer specifies the position, value, bulk and determination of plan and the first basis of the effect. Supreme literature review disrespect of this foundation effect and circumstance that often the effect must be approved and can caused by plan dissatisfaction. The physical first here that: There is no academic effect management in the construction of planning in Rwanda. This is Inspire the volumes of the literature reviews on the effect controlling in the construction industrial, breaks and value ended track persist for every day incident in the most construction of strategy. This is essential for examining the established as well compassionate of what actual the effect organization in the construction corporate. Often the related literature review illustration that the research sage gives the best accidental for effect organization of the preparation success, this is very small examination have been complete to suggestion the outcome of explicit technique at this stage on the planning presentation. This study purposes to pay material and within weight of Rwanda construction firms.

\subsection{Theoretical Framework}

\subsubsection{The Prospect theory}

Prospect theories is taking resolution below circumstances of effect(Tversky,.et al., 1979). Assumptions contained interior disagreement above wealth occupation offs.

Prospect Theory classified into tow section of making decision namely, expurgation, or enclosing, step, and the appraisal stage (Tversky, 1967). enclosing defined as the process of which an selection container exaggerated by the instruction and it is represented to a making choice. The appraisal stage of a panorama theory includes 2 sections the charge function and the weighting function. The value function is defined in terms of gains and fatalities comparative to the orientation opinion never footings of complete prosperity.

In prospect theory, value is a meaning of modification with an emphasis on starting argument such that modification is either harmful or encouraging. Prospect theory calculates that domain affects risk propensity. Losses have more emotional impact than an equivalent money of improvements and hence weighted many comprehensively due to making choice (Tversky \& Kahneman, 1975). 
2.5 Conceptual framework

Independent variable

Risk MGT technique

- Risk identification process

- Site selection process

- Budgetary process
Dependent variable

- Achievement of objective

- Profit maximization

- Delivered at time

- Delivered at Budget

Intervening variable

- Skills about risk management

- Technique application

Source: Primary data,2020

\section{Figure2.1: Conceptual framework}

Risk identification process goes to classify the spring and nature of menaces. Identification risk encompasses the recognition of impending menace occasion surroundings within the building plan and the explanation of effects errands (Wang,. et al., 2004). The empathy and extenuation of planning effect are vital phase with in handling efficacious plan (Carbone \& Tippet, 2004). The place has a durable inspiration of construction enterprise and structural characteristics and consequently the application of the plan. Manufacture decision regarding to position of speculation is compound, little planned and multi-criteria challenges (Jajac, Bilic, \& Adjuk, 2013). The location touches the group, massing; functionality; sustainability process and financial competence; safety and finally the artistic qualities of construction (GSA, 2001).

\subsection{Summary}

The appraisal of the writings exposed extensive variety of risk kinds and foundations in building projects, and that numerous risk organization technique can be working within organization of building plan to governor possible risks. Effect organization within building planning is an extensively investigated zone.

\subsection{Research Methodology}

\section{Introduction}

This chapter focused on research design, target population, sample size, sampling procedures, data collection procedures and data analysis techniques, methods and instruments of data collection, pilot study, instrument reliability, instrument validity and ethical considerations of the study. A discussion of each aspect of the research methodology was given hereunder, beginning with research design.

\subsection{Research Design}

The study adopted a descriptive survey design. A descriptive survey design allows for an in-depth analysis and understanding of a particular phenomenon as it exists in the present condition (Cooper and Schindler, 2008). In descriptive survey design, objectives are predetermined allowing data collection relevant and sufficient to the study problem (Kothari, 2004). By combining both quantitative and qualitative data collection procedures, descriptive survey design allowed a researcher to gather exhaustive information in a way that reduces cost of the data collection.

\subsection{Target Population}

The population in research refers to all items in a unit of inquiry (Kothari, 2011). The key respondents in construction industry were the target population, which comprised of 73 members who were the engineers, consultants, contractors and the construction staff of GTbank construction project. 


\subsection{Sample Design}

\subsubsection{Sample Size}

The number of items to be selected from the population to constitute a sample (Kothari, 2011) Therefore, the sample size of the population was calculated using Slovene's formula for estimating sample size (n) I.e. $\mathrm{n}=\frac{N}{1+N(e) 2}$
ISSN 2455-6378

Whereby; $n=$ required sample size $\mathrm{N}=$ population Size value of 0.1 )

$$
\mathrm{e}=\text { margin of error at } 10 \% \text { (Standard }
$$

$$
\begin{gathered}
\text { Therefore; } \mathrm{n}=\frac{73}{1+73(0.01)} 2 \quad \mathrm{n}= \\
\frac{73}{1+73(0.01)} \mathrm{n}=\frac{73}{1.73} \mathrm{n}=42 \text { Sample Size }
\end{gathered}
$$

Table 3. 1: Target population and sample size

\begin{tabular}{|l|c|c|c|}
\hline Respondents' category & Population & Sample size & percentage \\
\hline Engineers & 4 & 2 & $4.80 \%$ \\
\hline Consultants & 8 & 4 & $9.50 \%$ \\
\hline Contractors & 21 & 13 & $31 \%$ \\
\hline Bank Construction project staff & 40 & 23 & $54.70 \%$ \\
\hline Total & $\mathbf{7 3}$ & $\mathbf{4 2}$ & $\mathbf{1 0 0 \%}$ \\
\hline
\end{tabular}

Source: Researcher, 2020

Table 3.1: Illustrates the category of the respondents and the sample size from each category. Ideally, there were the total number of 4 engineers and 2 were randomly selected for sampling and out of the 8 consultants, 4 of them were also randomly selected for sampling. Contractors had a total number of 21 staff members and only 13 were randomly selected for sampling. The category, which were the majority, were the Bank Construction project staff whose total population was 40 and only 23 were equally sampled for the study.

\subsubsection{Sampling Technique}

Keith (2009) highlighted that a sampling is not independent of the other elements in a research project, particularly its research purposes and questions. Unsystematic technique has selected consultant, constructors, and staffing from the list of enumerated engineers. Random technique is the probability due to population place or possessions are randomly chosen in the study (Kombo \& Tromp, 2006). Therefore, during in this study 42 experienced who reimbursed the response form had chosen by applying purposive method for physically interviewed. Purposive sampling is a useful sampling method, which allows investigator to obtain data participants that one contemplates recognizes greatest theme substance (Walliman, 2011).

\section{4: Data Collection Methods}

\subsection{1: Data Collection Instrument}

The study was make use of both secondary and primary methods of collection of data. Selfadministered questionnaires were used to collect primary data from respondents. Journal articles from online data bases and books from Mount Kenya University Library was the primary source of secondary study data also interviewed were used in the collection of additional information.

\subsection{2: Administration of Data Collection Instruments}

After the approval of the proposal by Mount Kenya University (MKU), the researcher pursued a letter of introduction to GT Bank. The researcher then met the management to seek permission to administer the research instruments to the staffs and customers. The major research instrument, the questionnaire was given to technical staff and experts to get their comments on where changes would be needed. This expanded the validity and consistency of questionnaire after their input. After some modifications were made, it was readministered. The researcher then contacted respondents directly with questionnaires and requested them to express their views after clearly explaining to the respondents the purpose of the research.

\subsection{3: Validity and Reliability}

The content and validity of the questionnaire was ensured since the content covered the range of the general items being evaluated in the research. In this research case, all the main items in the questionnaire determined the actual dimensions on the risk management techniques and performance of construction a case of project of GT bank in Rwanda.The construct validity was guaranteed by ensuring that the questionnaire conformed to the general theoretical predictions guiding the study. Validity was also achieved through vetting by supervisors and peers. 
A reliability test was carried out to test the consistency of instruments being used in the project. A pilot study was conducted to establish procedures, materials, and parameters to be used in the main study.

\section{5: Data analysis procedure}

The information was collected, stored and coded in SPSS version 22.0. Data analysis was done using descriptive statistics. In this case, frequency tables and percentages were used. For descriptive statistics simple summaries were generated using SPSS version 22.0 from the observations made. Such summaries were quantitative, i.e. precipitating statistics and visuals, easy to understand graphs.

\subsection{Ethical Consideration}

The researcher commenced the data collection method after successfully defending the proposal at Mount Kenya University. Upon the acceptance of the proposal at the institution, the researcher was issued with the letter of introduction which stipulates the purpose of undertaking this exercise. The researcher then formulated a letter seeking for an appointment from the senior management team of GT Bank to book an appointment for collecting the data in their institution. A copy of introductory letter was attached to this appointment letter. After getting the acceptance, the researcher personally delivered the questionnaires to the respondents and waited for the respondents to fill the questionnaires. Semi structured interview was done to those who sought to have a quick session with the researcher

\subsection{Findings and Discussion}

\subsection{Introduction}

This chapter was focused on the analysis and interpretation of data collected from the field of the study. The data was compiled, categorized and then presented using statistical tables and figures backed up by frequency and percentage presentation. Interpretation of findings was done based on frequencies and percentage responses to each particular question and each objective was addressed by the analysis.

\subsection{Response Rate}

Altman and Bland (2007) indicate that obtaining a response rate that exceeds a half of the selected samples is preferable because the missing data is always inevitable since some respondents decided
ISSN 2455-6378

not to respond to some items or the whole questionnaire. In this study, all 42 questionnaires were completed.

\subsection{Demographic characteristics of the respondents}

This section is very important as it helped the researcher to determine respondents' backgrounds, which have implication on the relevancy, validity and reliability of data provided. This section concentrates on describing data collected on the respondents regarding their gender, age group, level of education and working experience. The main findings were presented in tables with brief interpretations of the tables in the subsequent sections.

\subsection{Presentation of the Research Findings}

The researcher presents the results from the field as pull out from the information collected tools specifically questionnaires and interview guide. The collected information was then represented in form of tables while analysis and interpretation was based on the frequencies and \% of respondents' opinions. Every objective was controlled chronologically as represented with introduction. It is vital to remember that, this exploration was guided by 3 main purpose of the study, namely;

1. To determine the extent to which risk identification process influence performance of the construction project of GTbank

2. To determine the extent to which site selection process affect performance of the construction project of GTbank

3. To determine the extent to which the budgetary process affect the performance of the construction project of GTbank

4.3.1: Risk identification process on the performance of the construction project of GTbank

The first aim was identifying level of functional devoted to risk identification performs with project stage under building scheme in Rwanda. Whereby 42 participants were applied. There had been a risk identification procedure unto planning stage of $92.5 \%$ while the surveyed planning. Therefore, $60 \%$ of the planning, and risk managing procedure was familiar while it was recognized in $40 \%$ of the plan.

Table 4.1 proves the level of reputation involved to the risk identification procedures. 
Table 4.1 Level of importance attached to risk identification practices

\begin{tabular}{|c|c|c|c|c|c|}
\hline $\begin{array}{c}\text { Evaluation of the } \\
\text { level of importance }\end{array}$ & $\begin{array}{c}\text { Clarity of space } \\
\text { use requirement }\end{array}$ & $\begin{array}{c}\text { Consultants } \\
\text { competence }\end{array}$ & $\begin{array}{c}\text { Availability of } \\
\text { suitable land }\end{array}$ & $\begin{array}{c}\text { Estimated } \\
\text { project Time }\end{array}$ & $\begin{array}{c}\text { Budget } \\
\text { Availabilit } \\
\mathbf{y}\end{array}$ \\
\hline Very important & $31 \%$ & $26 \%$ & $24 \%$ & $19 \%$ & $29 \%$ \\
\hline Fairly important & $33 \%$ & $62 \%$ & $55 \%$ & $52 \%$ & $36 \%$ \\
\hline Not so important & $29 \%$ & $10 \%$ & $19 \%$ & $24 \%$ & $31 \%$ \\
\hline Unimportant & $7 \%$ & $2 \%$ & $2 \%$ & $5 \%$ & $5 \%$ \\
\hline Total Number & 42 & 42 & 42 & 42 & 42 \\
\hline Total \% & $100 \%$ & $100 \%$ & $100 \%$ & $100 \%$ & $100 \%$ \\
\hline
\end{tabular}

\section{Source: Primary data, 2020}

The simplicity of astronomical practice as risk was painstaking very significantly of $31 \%$; central by $33 \%$; not so importance $29 \%$, and unimportance $7 \%$. $62 \%$ of the participants umpired the level of the study about consultants as justly important was $26 \%$ as very importance, and only $2 \%$ assumed it as unimportance. The accessibility of appropriate parcel and place was arbitrated to be honestly importance of $55 \%$, and the answers; very importance was $24 \%$; and never so importance of
19\%. The suggestion or expectation achievement period of risk was mediated as justly importance of $52 \%$ and was an answers, very importance was presented with $24 \%$; and not so importance with $24 \%$. The accessibility of adequate financial plan was observed as not so importance of $36 \%$ of the participant $31 \%$ was arbitrating it as fairly importance. Solitary $31 \%$ of the participants supposed the accessibility of inexpensive as existence very importance.

Table 4.2: Project Phase in which the respondents participated

\begin{tabular}{|l|c|c|}
\hline Participation & Number & Percentage \\
\hline Planning & 6 & $14 \%$ \\
\hline Design & 15 & $36 \%$ \\
\hline Procurement & 1 & $2 \%$ \\
\hline Construction works & 20 & $48 \%$ \\
\hline Total & 42 & $100 \%$ \\
\hline
\end{tabular}

\section{Source: primary data,2020}

About $48 \%$ of the participants had contributed with in the building works stage and has presented with $36 \%$ in design, $14 \%$ in project and only $2 \%$ in the procurement or bid process. Unless $87.5 \%$ of the plans identified risks appearance. The crucial risks identification due to interviewed were uncomplimentary pulverized situations, reformed conventions, opportunity sneak, discrepancies, adjournments in agreement, customers' catastrophe to receive planning, continued shortcomings

Table 4.3. Impact on the project cost for identified risks responsibility time and hopeless consultants. Within various plans of identification risk procedure was informal. Opposed pulverized circumstances dangers occurred though often anticipated and had some impact on cost and schedule according to the conference defendants. Therefore, were examples where stipulations were improved through building workings and previous absent everything were additional strengthen.

\begin{tabular}{|l|c|c|}
\hline Impact & Number & \% \\
\hline Fairly large Variations (20-40\%) & 12 & 28.6 \\
\hline Fairly small Variations (10-20\%) & 14 & 33.3 \\
\hline Every large Variation (over 40\%) & 6 & 14.3 \\
\hline Every small (1-10\% variations) & 4 & 9.5 \\
\hline Risk does not occur & 6 & 14.3 \\
\hline Grand Total & 42 & 100 \\
\hline
\end{tabular}

Source: primary data,2020 
There were various and diverse facts mentioned as motives why these menaces befallen. Many of effects occasioned within supplementary expenses and deferred plans achievement on timely. Unpredicted effects were befallen on $85.7 \%$ of the schemes. These menaces were caused by $10-$ $20 \%$ planning cost on $38.9 \%$ of the plans, and 20 $40 \%$ variations within $33.3 \%$ of the pans, and over $40 \%$ variations within $16.7 \%$ of the planning. While $39 \%$ of the opinions said that both team groups had the better opportunities to accomplish price variations while $82.5 \%$ believed that the customers had the better opportunities to achieve late expenditures jeopardies. The consultants had the better coincidental to accomplish inappropriate design response related to risks of $53.7 \%$. The customer had better opportunities of accomplishing design fluctuations rendering to $48 \%$ of the accused while $36.6 \%$ of the answers

Table 4.4. Time of Site selection

\begin{tabular}{|l|c|c|}
\hline Selection time & Number & \% \\
\hline Before plan & 10 & 23.8 \\
\hline Plan & 21 & 50 \\
\hline Designing & 8 & 19 \\
\hline Works Construction & 3 & 7.1 \\
\hline Grand Total & $\mathbf{4 2}$ & $\mathbf{1 0 0}$ \\
\hline
\end{tabular}

Source: primary data,2020

The project site was nominated thru the project stage of $50 \%$ of the scheme; before planning in $23.8 \%$ and during design in $19 \%$ of the project surveyed.

The interviews indicated that in most projects the site was selected by client but validated by supposed that the consultants had better achievement of handling design alteration. $75 \%$ of the answers had said that the consultants had good opportunity to manage interruptions in project. The worker had the good opportunities to control building postponements rendering to $73.8 \%$ of the defendants while the customers had the good opportunities within management of risk of inappropriate site conditions according to $58.5 \%$ of the respondents. The contractor had the best chance in dealing the effect of missing of tools rendering to $56.1 \%$ of the defendants.

4.3. 2 Site selection process and performance of the construction project of GTbank

Objective two of this research pursued to inaugurate the level of influence of site selection on as a risk factor influences performance of the construction project.

Table 4.5. Involvements in site selection

\begin{tabular}{|l|c|c|}
\hline Team member & Number & \% Cases \\
\hline Architect/engineer & 4 & 9.5 \\
\hline Clients & 41 & 97.6 \\
\hline Project managers & 8 & 19 \\
\hline Contractors & 4 & 9.5 \\
\hline
\end{tabular}

Source: primary data,2020

The customer / clients was convoluted in $97.6 \%$ of the plan in site selection, the consultants in $9.5 \%$, the planning manager in $19 \%$ and the contractors $9.5 \%$ of the plan. $43.9 \%$ of the participants were not indisputable whether there was another land presented for the surveyed plan while 36.6 and 19.5 were conscious and not aware correspondingly of obtainability substitute land. Whereby $54.8 \%$ of the consultants. Later during design stage. Most projects had increased costs in substructure works. Certain positions were cited as being very challenging with more absorbent walls. 
Table 4.6. Site evaluation

\begin{tabular}{|l|c|c|c|c|c|}
\hline Evaluation & Suitability & Slope & $\begin{array}{c}\text { Site works contribution } \\
\text { to cost variation }\end{array}$ & $\begin{array}{c}\text { Compliance to } \\
\text { environmental } \\
\text { regulation }\end{array}$ & $\begin{array}{c}\text { Availability of } \\
\text { roads }\end{array}$ \\
\hline Very Good & 26.2 & 16.7 & 11.9 & 11.9 & 23.8 \\
\hline Fairly Good & 54.8 & 57.1 & 45.2 & 61.9 & 50 \\
\hline Fairly Bad & 9.5 & 19 & 26.2 & 19 & 21.4 \\
\hline Very Bad & 9.5 & 7.1 & 16.7 & 7.1 & 4.8 \\
\hline & 42 & 42 & 42 & 42 & 42 \\
\hline & 100 & 100 & 100 & 100 & 100 \\
\hline
\end{tabular}

Source: primary data,2020

The site workings involvement to price variations was appraised as impartially best by $45.2 \%$ of the answers impartially wrong of $26.2 \%$; very bad by $16.7 \%$ and very good by $11.9 \%$ of the respondents.
The amenability with conservation regulations and openness was evaluated as fairly good $61.9 \%$ and $50 \%$ responses.

Table 4.7 Evaluation site

\begin{tabular}{|l|c|c|c|c|c|c|}
\hline & $\begin{array}{c}\text { Availability } \\
\text { of Service }\end{array}$ & $\begin{array}{c}\text { Ease of } \\
\text { construction }\end{array}$ & $\begin{array}{c}\text { Construction } \\
\text { Time }\end{array}$ & $\begin{array}{c}\text { Availabilty of } \\
\text { Landfill }\end{array}$ & Utility cost & $\begin{array}{c}\text { Attractiveness of } \\
\text { the location }\end{array}$ \\
\hline Very Good & 19 & 4.8 & 4.8 & 4.8 & 9.5 & 31 \\
\hline Fairly Good & 52.4 & 61.9 & 73.8 & 40.5 & 35.7 & 61.9 \\
\hline Fairly Bad & 23.8 & 21.4 & 16.7 & 50 & 50 & 4.8 \\
\hline Very Bad & 4.8 & 11.9 & 4.8 & 4.8 & 4.8 & 2.4 \\
\hline & 42 & 42 & 42 & 42 & 42 & 42 \\
\hline & 100 & 100 & 100 & 100 & 100 & 100 \\
\hline
\end{tabular}

\section{Source: Primary data,2020}

Accessibilities of facilities was estimated as fairly best and very good offered by $76.2 \%$ of the responses. The easiness of building in relative to quarry and substance mechanism was appraised as better on $66 \%$ of the scheme and very wrong of $11.9 \%$ of the plan. The obtainability of land-living for mined materials was immoral in $55 \%$ of the plan. The influence of efficacies to build charges was assessed as evil in $57 \%$ of the plan. The draw of the location was appraised as good in over $90 \%$ of the developments. The charge of land-living attainment was good by $87.5 \%$ of the plan plotted. The performance prices of position effort in contrast with approximations in the proposal mandibles of amounts among $1-10 \%$ in $46.3 \%$ of the plan, $10-20 \%$ and within $24.4 \%$ of the plan; over $20 \%$ additional the guesstimate in $19.5 \%$ of the scheme and lower than the approximations in $9.8 \%$ of the plan as well as there is similar study done by (Jajac et al., 2013).

4.3.3 Preliminary budgetary processes and performance of the construction project of GTbank

Objective three of this research sought to determine the influence of budgetary processes as one of the risk factors on the performance of the GTbank construction project as presented in table 4.9 below

Table 4.9. Time budget and project development

\begin{tabular}{|l|c|c|}
\hline Phase & \% (Budget development) & \% (Schedule development) \\
\hline Planning plan & 64.3 & 71.4 \\
\hline Design designing & 35.7 & 19 \\
\hline Working Construction & 0 & 0 \\
\hline Total & 100 & 90.5 \\
\hline
\end{tabular}

\section{Source: Primary data,2020}

The project preliminary budget was projected through the arrangement stage of $54 \%$ of the schedule; beforehand plan of $25 \%$ and through designing by $15 \%$ of the plans plotted.
The customer was complicated of $98 \%$ of the planning with in initial budget and project growth, the consultants presented by $23 \%$ of the planning, the planning managers in $13 \%$ and the contractor in $4.1 \%$ of the projects. The interviews indicated that 
preliminary budget was industrialized by the customer alone but was advanced familiar to mentor's intimate estimate in maximum developments.

Table 4.10. Budget against bid price

\begin{tabular}{|l|c|}
\hline Variables & Project percentage \\
\hline Over $40 \%$ less than actual & 73.8 \\
\hline $20-40-2 \%$ less than actual & 7.1 \\
\hline $10-20 \%$ less than actual & 4.8 \\
\hline As actual & 14.3 \\
\hline More than actual & 0 \\
\hline Total & $\mathbf{1 0 0}$ \\
\hline
\end{tabular}

\section{Source: Primary data,2020}

During $64 \%$ of the plan's preliminary budget was above $50 \%$ subordinate the small refunded bid price and the consultant's estimation amid of design. $45 \%$ of the schedule were shut after design stage when it became clear that they were not feasible. The durations for the consultancy the customer's attaining team unaccompanied in projected facilities and building works over $70 \%$ of the projects. The main criteria in time estimate in $64 \%$ of the projects were agreement to outside budget timetables like administration economic year. Consultancy facilities were hurried to encounter the monetary year shutting goals and building works time schedules were attuned to fit within monetary plans.

.Table 4.11 Evaluation of project performance

\begin{tabular}{|l|c|c|c|c|}
\hline Perception & Functionality & Time & Cost & Communication \\
\hline Strongly agree & 54.8 & 45.2 & 54.8 & 64.3 \\
\hline Agree & & & & 10.5 \\
\hline Neutral & 26.2 & 9.5 & 9.5 & 23.8 \\
\hline Disagree & 16.7 & 28.6 & 21.4 & 2.4 \\
\hline Strongly disagree & 2.4 & 16.7 & 14.3 & $\mathbf{4 2}$ \\
\hline Number & $\mathbf{4 2}$ & $\mathbf{4 2}$ & $\mathbf{4 2}$ & $\mathbf{1 0 0}$ \\
\hline \% & $\mathbf{1 0 0}$ & $\mathbf{1 0 0}$ & $\mathbf{1 0 0}$ & \\
\hline
\end{tabular}

\section{Source: Primary data,2020}

According to table $4.9,54.8 \%$ of the respondents had a strongly agree evaluation of the functionality of the project as; $26.2 \%$ neither agreed nor disagreed with the evaluation of the functionality of the project and $16.7 \%$ disagreed with the functionality and only $2.4 \%$ strongly disagreed. On the other hand, $45.2 \%$ of the respondents strongly agreed with the evaluation of the project based on time factor, $9.5 \%$ were neutral, $28.6 \%$ disagreed with the time factor and only 16.7 strongly disagreed with the time factor based on project performance and project completion. When respondents were asked about the project cost,
$54.8 \%$ strongly agreed with the cost efficiency, $9.5 \%$ were undecided yet $21.4 \%$ of the respondents disagreed with the cost effectiveness and only $14.3 \%$ strongly agreed with this prospect. Finally, the respondents were asked to evaluate the project based on communication efficiency, $64.3 \%$ of the respondents were strongly in agreement with the communication efficiency, $10.4 \%$ were neutral and $23.8 \%$ disagreed with the prospect of communication efficiency. Only $4.2 \%$ of the respondents strongly disagreed with the project communication efficiency.

\subsection{3: Correlation of Budgetary process on project performance}

\begin{tabular}{|l|l|c|c|}
\hline & & Budgetary process & Project performance \\
\hline Budgetary process & Pearson correlation & 1 & $.678^{* * *}$ \\
\hline & Single (2- tailed) & & 0 \\
\hline & $\mathrm{N}$ & 42 & 117 \\
\hline Project performance & Pearson correlation & $.678^{* * *}$ & 1 \\
\hline & Single (2- tailed) & 0 & 123 \\
\hline & $\mathrm{N}$ & 42 &. \\
\hline
\end{tabular}


Budgetary process was found to have a strong positive correlation with project performance with positive correlation of $0.678, p$-value $=0.000$ at the significant level of 0.01 . This implied that, the increase and proper management of the budgetary process had the power to improve performance in positive ways. This confirmed that; establishment of a suitable budget and time schedules in a very critical success factor to the construction project without which, failure is deemed to happen.

\section{Summary, Conclusions and Recommendations}

\subsection{Introduction}

This chapter elucidates in detail the overall summary of the research project. The research conclusion is also made in line with the findings and implications of every particular research objective. The chapter also gives possible recommendations made by the researcher regarding the variable of the research. The researcher further identifies crucial areas for future research. Therefore, the overall aim of this chapter is to present the findings in a brief format for easy interpretation by other readers.

\section{1: Summary of findings}

The aim of this study is evaluate the effects of risk management techniques regarding to performance of construction project of GTBank in Rwanda. Risk management is renowned a vital implementation in mandate to succeed good presentation of building plan. Realization within building scheme is designated by its presentation with in attainment of purpose of expansion of costs, distribution towards period budgeting. Imprecise inexpensive may prime to excellence cooperation and differences within neither the customer, end-user, nor project team being covered pleased at the culmination.

Edifice projects with in Rwanda and usually region and the universal running more effect of existence healthy above economical and meaningfully nighttime.

Concerning the consultants with in location choice and corroboration in structure schedule was exposed to be a significant risk managing preparation to moderate the menaces of outlays and period of variation through opposed site settings. The investigation showed that many scheme in Rwanda had several input from a trained engineer and draftsman. The glassy of skills in assembly interrelated parks was illustrious to be more, on $85 \%$ of the response partaking a degree. Though, various answers had not deliberate about risk management. While the revision designated that risk management was extensively experienced at
ISSN 2455-6378

$92 \%$, the course was mostly relaxed. High results indicated management risk exercise significant. There was more occurrence of occurrence of recognized risks, at $85.7 \%$. This indicates that the process of risk management was not adequate and no measures were put in place to alleviate the jeopardies. The influence of these menaces was moderately more and occasioned in $10 \%$ to $40 \%$ priced dissimilarity in $72 \%$ of the scheme surveyed.

The study carried out that the referring engineers and architects were frequently chosen earlier the enterprise stage of a plan. It remained only $14.3 \%$ of the scheme that the professionals were chosen beforehand scheme preparation. This predestined that, the scheme did not advantage from specialized contribution at preparation phase. The most secondhand technique chosen and used for experts was the excellence and charges depend on assortment method. Greatest defendants assessed their scheme as best with in significantly, timely, price and communications. Though, the presentation $19.5 \%$ to $47 \%$ of the budget plotted, was assessed as corrupt in the identical strictures of function, time, cost and communication. Time performance was the lowliest limit with $45.2 \%$ of the schemes consuming and have been appraised as bad and very bad. Charge was the additional bad recital parameter of $35.7 \%$ of the schemes being bad and very bad.

\subsection{Conclusions}

The study projected identified an ineffective level of risk management techniques at construction project in Rwanda. This was since high methods were informal, and high building team groups had not yet intentional risk management or project management. The effect of recognized but absolute effects was originating to be great. Numerous scheme team group had altered opportunities of justifying the many dangers but customers had the good opportunities with in management more of the risks. Subsequently, the customers alone, did site assortment and authentication, which frequently ensues at development stage. This principal to inappropriate locations that augmented priced and period for quarry and underpinning jobs. The finish operators were not yet included with in requirements identification and validation procedure the GT bank building scheme surveyed. Obedience with in outside party-political approach and society plans was the general principles with in requirements documentation. There were transformation guidelines with in the planning ascending from modification within desire thru structure workings. The price and timetable development process was inefficient and led to inaccurate estimates that later negatively pretentious development presentation. 


\subsection{Recommendations}

The research project identified ineffective risk management practice at planning stage as a foremost source of deprived plan performance.

This study recommends that formal and structured risk management preparation during planning and within envelopment of assembly authorities and end managers.

The study suggests unceasing expansion meetings with in risk management for both specialists with in Rwanda and particular those with in structure schemes development section of all secluded and administration creators.

The study those who developers would recollect the facilities of capable consulting designer or engineer through, and, this consultant would be sited at highest choice conferences to information on building challenges.

\subsection{Areas for Future Research}

Further investigation is required with in the location to harvest a comprehensive assembly scheme planning controller for allocation by inventors and administration units. Not only there is also prerequisite for auxiliary examination on the possessions of the draftsman and engineer mixture method on assignment show. There is also prerequisite for supplementary enquiry on the education gaps with in the architectures and engineers training offered by those architects and engineers had not yet experienced about risk management.

\section{DEDICATION}

This work is recognized to my lovely Husband, Children, Parents and Relatives for their love, courage, upbringing and parental guidance. They for eternity encouragement me to shove on with the writing of this thesis.

\section{ACKNOWLEDGEMENTS}

This study could not have been completed without the assistance and support of others. Firstly, I am grateful to the Almighty God for His divine guidance during my academic progress and the production of this paper. I am equally indebted to my supervisor Dr. Claude Rusibana for the valuable time he sacrificed to guide me through the compilation of this work. Last, but not least, I extend my gratitude the management of GT Bank who settled me permission to use their construction project as a case study and provided some data that helped me finalize this paper. Finally, I be grateful for the support I kept obtaining from my beloved husband and Children.

\section{References}

[1] Ahmed, A., Kayis, B., \& Amornsawadwatana, S. (2007). A review of techniques for risk management in projects. Benchmark International Journal, 14(1), 22-36.

[2] Archibald, R. D. (1976). Managing HighTechnology Programs and Projects. New York:

[3] Assaf, S., \& Al-Hejji, S. (2006). Causes of delay in large construction projects. InternationalJournal of Project Management, 24(4), 349-357. Retrieved from

[4] Backstrom, C. H., \& Hursh-Cesar, G. (1981). Survey research (2nd ed.). New york: John Wiley \& Sons.

[5] Bernouli, D. (1934, ). Exposition of a new theory on the measurement of risk. Econometrica, 22(1), 22-36.

[6] Carbone, T. A., \& Tippet, D. D. (2004). Project Risk Management Using the Project Risk FMEA. Engineering Management Journal, 16(4), 28-35. Retrieved from http://www.fmeainfocentre.com

[7] Carmines, E. G., \& Zeller, A. R. (1979). Reliability and validity Assessment. Beverly Hills, CA: Sage.

[8] Ceric, A. (2003). A framework for processdriven risk managementin construction a framework for process-driven risk management in construction projects. Salford, Uk:University of Salford.

[9] Chapman, C., \& Ward, S. (2003). Processes, Techniques and Insights (2nd ed.). Chichester, England: Wiley.

[10] Chapman, C., \& Ward, S. (2007). Project risk management: Process, techniques and insights (2nd ed.). Chichester: John Wiley.

[11] Chapman C.B. (1983, November). Risk analysis: Testing some prejudices. European

[12] Journal of Operational Research, 14, 238247.

Retrieved fromhttp://www.sciencedirect.com

[13] Choge, K. J., \& Muturi, W. M. (2014). Factors affecting adherence to cost estimates: A survey of construction projects of Kenya National Highways Authority. InternationalJournal of Social Sciences and Entrepreneurship, 1, 689-705.

[14] Clough, R. H., Sears, S. K., \& Sears, G. A. (2005 ). Construction Contracting: A Practical

[15] Guide to Company Management (7th ed.). London: Wiley.

[16] Cretu, O., Stewart, R. B., \& Berends, T. (2011). Risk management for design andconstruction(RSMeans). Hoboken: John Wiley \& Sons.

[17] Eskesen, S. D., Tengborg, P., Kampmann, J., \& Veicherts, T. H. (2004). Guidelines 
fortunnelling risk management, International Tunnelling Association (19(3)).

[18] Fageha, M. K., \& Aibinu, A. A. (2014). A Procedure for Involving Stakeholders when Measuring ProjectScope Definition Completeness at Pre-Project Planning Stage. AIPM NATIONAL 2014 CONFERENCE PROCEEDINGS, 1-8. Retrieved from

[19] Fellows, R., \& Liu, A. (2008). Research methods for construction (3rd ed.). Chichester:

[20] Wiley-Blackwell.

[21] Flanagan, R., Norman, G., \& Chapman, R. (2006). Risk management and construction (2nd ed.). Oxford: Blackwell Publishers.

[22] GSA (2001). The Site Selection Guide $\left(1^{\text {st }}\right.$ ed.). Washington DC: AIA.

[23] Gkritza, K., \& Labi, S. (2008). Estimating Cost Discrepancies in Highway Contracts: Multistep Econometric Approach. Journal of Construction Engineering andManagement, 134(12), 935-962.

[24] ICE (2005). RAMP - Risk Analysis and Management for Projects: A Strategic Framework forManaging Project Risk and its Financial Implications (2nd ed.). London: ThomasTelford Publishing.

[25] ISO 31000:2009 Risk management -Principles and guidelines. (2009). Retrieved from www.iso.org

[26] Jajac, N., Bilic, I., \& Adjuk, A. (2013). Decision suppport concept to management of construction projects- problem of construction site selection. Croatian OperationalResearch Review (CRORR), 4, 235-245

[27] Kerzner, H. (2009). Project Management: A systems approach to planning, scheduling, andcontrolling (10th ed.). New Jersy: John Wiley and Sons.

[28] Klemetti, A. (2006). Risk Management in Construction Project Networks. Helsinki: Helsinki University of Technology.

[29] Kombo, D. K., \& Tromp, D. A. (2006). Project and Thesis Writing: An Introduction. Nairobi: Paulines Publications' Africa.

[30] Kumar, R. (2005). Research Methodology-A Step-by-Step Guide for Beginners (2nd ed.). Singapore: Pearson Education.

[31] Ministry of Finance and Economic planning. (2014). Budget Framework paper 2014/2015-2016/2017. Retrieved from http://www.minecofin.gov.rw

[32] Morris, P., \& Hough, G. H. (1988). The Anatomy of Major Projects: A Study of the Reality of

[33] Project Management (1st ed.). New York: Wiley.
ISSN 2455-6378

[34] Neumann, J., \& Morgenstern, O. (1953). Theory of Games and Economic Behaviour (3rd ed.). Princeton, NJ: Princeton University Press.

[35] Office of the Auditor General of State Finances. (2013). Report of the Auditor General of State Finances for the year ended 30th June 2013. Retrieved from www.oag.gov.rw

[36] Ryan, G., \& Bernard, H. R. (2000). Data management and analysis methods. Thousand Oaks,CA: Sage.

[37] Smith, N. J. (2006). Managing risk in construction projects (2nd ed.). London: Blackwell Publishing.

[38] Tversky, A. (1967). additivity, utility, and subjective probability. Journal of MathematicalPsychology, 4, 175-201.

[39] Tversky, A., \& Kahneman, D. (1975). Judgement under uncertainty: Heuristics and Biases. Science, 185, 1124-1131.

[40] Tversky, A., \& Kahneman, D. (1979, March). Prospect Theory: An analysis of Decision under Risk. Econometrica, 47(2), 263291.

[41] Utilize Cost Management Throughout the Planning, Design, and Development Process. (2011). Retrieved 14-05-2015, from http://www.wbdg.org/design/utilize_manageme nt.php

[42] Walewski, J., Gibson, G., \& Vine, E. (2002). Improving International capital projects risk analysis and management. Proceedings of the project management Insitute research conference. Seattle, WA

[43] Walewski, J., Gibson, G., \& Vines, E. (Eds.). (2002). Improving International CapitalProject Risk Analysis and Management. . Seattle WA: .

[44] Wallace, P., \& Blumkin, M. (2007). Major Construction Projects: Improving Governance and Managing Risks. Retrieved from www.deloitte.com

[45] Walliman, N. (2011). Your Research Project: Designing and Planning Your Work (3rd ed.). London: Sage.

[46] Wang, S. Q., Dulaimi, M. F., \& Aguria, M. Y. (2004). Risk Management Framework for Construction Projects in Developing Countries. Construction ManagementEconomics, 22(3), 237-252.

[47] Wang, X., \& Huang, J. (2006). The relationships between key stakeholders' project

[48] performance and project success: Perceptions of Chinese construction supervising engineers. International journal of project management, 24, 253.

[49] Yamane, T. (1967). Statistics, An introductory Analysis (2nd ed.). New York: Harper and Row. 
[50] Zhou, P. X., Zhang, G. M., \& Wang, J. (2007). Understanding the Key Risks in
ISSN 2455-6378

Construction Projects in China. International Journal of Project Management, 25, 601-614. 